\title{
MIMEO-POLÍTICAS. LOS SIMULACROS DE LA CIUDAD EN EL POLÍTICO DE PLATÓN
}

\author{
Juan Antonio González de Requena Farré \\ Universidad Complutense de Madrid \\ juannelly@surnet.cl
}

\begin{abstract}
Resumen
La concepción platónica de la política ha sido un modelo para aquellos que intentan establecer un principio firme de nuestras prácticas políticas compartidas; de hecho, hay cierta política del arje en los diálogos de Platón: la ciudad ha de ser gobernada por aquellos que tengan acceso a un conocimiento privilegiado del arje de la polis, de modo que puedan comprender el principio interno de la comunidad y realizar un orden armonioso dentro de la ciudad. Este artículo trata de explorar la imposibilidad de tal intento: el Político de Platón ilustra cómo, dentro de nuestras ciudades humanas, no hay una política regia del arje; como el propio Platón ejemplificó en sus diálogos, el arte de la política se ocupa de la construcción de simulacros, mitos y paradigmas, los cuales nos permiten tener una imagen de un arte político que no podemos definir. Así, el arte político deviene mimeo-política, una tejne de tejer simulacros para construir la segunda mejor ciudad.
\end{abstract}

Palabras Clave: política del arje, arte político, simulacro, mitos políticos, paradigmas de la política.

\section{Abstract}

Plato's conception of politics has been a model for those who try to establish a secure principle for our shared political practices; as a matter of fact, there is a certain politics of the arkhe in Plato's dialogues: the city has to be governed by those who had access to a privileged knowledge of the arkhe of the polis, so that they could understand the inner principle of the community and realize an harmonious order within the city. This article tries to explore the impossibility of such an attempt: Plato's Statesman illustrates how, within our human cities, there is not a royal politics of the arkhe; as Plato himself showed in his dialogues, the art of politics is concerned with the construction of simulacra, myths and paradigms, which allow us to have an image of a political art that we cannot define. So, the political art becomes mimeo-politics, a tekhne of weaving simulacra in order to construct the second best city.

KEYWORDS: Politics of arkhe, political art, simulacrum, political myths, political paradigms. 


\section{Introducción. El fundamento de la "arquipolítica"}

$\overline{R A}$ Cuando rememoramos nuestra deriva histórico-filosófica, topamos con un trayecto decisivo que ha hecho de la obsesión por la fundamentación de lo político una auténtica política del fundamento. Semejante "fundacionismo" político parece asumir que la única manera de dar sentido a nuestras prácticas e instituciones compartidas, así como el único modo de redescribir la trama público-polémica de nuestra convivencia política pasa por el establecimiento de un principio ideal o fundamento originario, que permita conjurar la contingencia y conflictividad de nuestras iniciativas políticas. Sin duda, aunque el "fundacionismo" filosófico-político ha marcado gran parte de la historia del pensamiento político occidental, su planteamiento paradigmático se encuentra en los diálogos platónicos; así, pues, parece ser que nuevamente habremos de escribir un comentario a pie de página de los textos de Platón, si es que queremos entender el núcleo problemático de nuestra filosofía política.

Ciertamente, en Platón hallamos una búsqueda intensa y comprometida de aquel principio fundamental que permite recrear cierta comunidad ideal acorde con el orden de la razón. Y es que la armoniosa organización de un equilibrio de conjunto, así como la constitución de un orden correcto en la comunidad política, requiere-según Platón- del conocimiento de la totalidad y de la unidad de lo múltiple de la polis, tanto en su relación consigo misma, como en relación con otros estados; solo conociendo el principio, criterio y molde correctos sería, por tanto, factible ese autogobierno, a través del cual la polis pone orden en sí misma, y logra su unidad autosuficiente. En ese sentido, la política platónica no solo se perfila como "filosofía política", o sea, como búsqueda noética y alumbramiento eidético de los principios del ordenamiento político correcto; además, se configura como una política de los principios, esto es, como una autoimposición del fundamento o arje en la constitución misma de la comunidad política.

No es de extrañar que Jacques Rancière se haya referido a esta política del arje como "arquipolítica"; ciertamente, en la arquipolítica platónica se trata de realizar efectivamente el arje como principio interno de la comunidad, de modo que este fundamento interior se manifieste en todos los aspectos y funciones de la vida compartida (Rancière 1996, pp. 88-93). Solo así -sostiene Rancière- la politeia platónica se opone a toda la gama de regímenes defectuosos: en tanto que régimen que realiza el principio de interioridad de la comunidad, y funda la unidad originaria de la comunidad política (Rancière 1996, pág. 86). La arquipolítica constituiría, por tanto, el régimen de lo mismo, la unidad integral de la comunidad en su esencia y fundamento, que se expresan en todas las funciones y actividades de la polis (Rancière 1996, pp. 85-87). De hecho, el principio de interioridad de la comunidad es uno con la distribución de las partes y funciones comunitarias; y es que la polis se funda-según Platón- en esa división interna de funciones y partes (así como en la reciprocidad 
de los intercambios), la cual realiza y pone de manifiesto el equilibrio interno y la armonía, que hacen de la ciudad un "alojamiento común"1.

Así, pues, en tanto que régimen de lo uno distribuido en partes y funciones, y como encarnación del principio interior de la comunidad, la arquipolítica platónica apunta -según Rancière- a la constitución de un auténtico organismo social, animado por el alma de las funciones comunitarias, y que insufla a cada parte funcional su principio vital (Rancière 1996, p. 87). Este paradigma organológico, que compara a la polis con un cuerpo animado por el alma misma de la comunidad, se funda -en el contexto de la arquipolítica platónica-en cierta analogía con el alma del individuo; no en vano, Platón establece que existe cierta correspondencia entre las partes, funciones y fines del alma individual, por un lado, y aquellos principios anímicos comunitarios que se manifiestan en la polis, por el otro lado (Platón, República, 441c). De ese modo, a los elementos racional, irascible y concupiscente, que son propios del alma individual, corresponderían las funciones comunitarias: el gobierno, la custodia y el abastecimiento. Asimismo, la polis y el ciudadano han de lograr la excelencia en cada una de sus funciones, ya se trate de la sabiduría en la conducción racional, del valor para contener las pasiones irracionales o de la moderación que surge de la obediencia a la razón. Por otra parte, tanto en el caso del alma individual, como en el de la comunitaria, la justicia se asimila a cierta forma de excelencia que pasa por el reparto de las funciones, de manera que cada parte haga lo suyo y se haga cargo de lo propio, sin interferir en los asuntos de las demás (República, 427e-443e). En ese sentido, la injusticia, es decir, la dispersión e intromisión de las partes, constituye -según Platón- tanto la enfermedad del alma como la ruina de la polis (República, 434b-c y 444b-c).

Así, pues, -como Rancière sostiene- la arquipolítica platónica depende de cierto equilibrio proporcional, que permitiría armonizar la unidad de conjunto de la comunidad; se trata de establecer una equivalencia proporcional, o sea, una igualdad geométrica, en virtud de la cual se llevaría a cabo una distribución "justa" de las partes, un reparto que ajustase la igualdad y corrigiera el reparto, considerando las desigualdades "naturales" que se siguen de la división de partes y funciones en la polis. En la arquipolítica platónica, todo pasa, entonces, -según Rancière- por suplementar el cálculo relativo de lo más y lo menos (así como la equivalencia simple de la medida), en que se basa la igualdad aritmética, reemplazándolo por la justa medida común del orden proporcional, auténtica réplica del equilibrio del cosmos, que posibilita la naturalización del reparto comunitario y, por ende, la realización integral de la physis en el nomos de la ciudad (p. 85). En ese sentido, la arquipolítica requiere también de una orquestación armónica de sones, tropismos y discursos, así como despliega toda

No en vano, el acta de fundación de la ciudad coincide prácticamente, en la versión platónica, con el principio de la división del trabajo, tal y como Sócrates lo plantea: "En tal caso, cuando un hombre se asocia con otro por una necesidad, con otro por otra necesidad, habiendo necesidad de muchas cosas, llegan a congregarse en una sola morada muchos hombres para asociarse y auxiliarse. ¿No daremos a este alojamiento común el nombre de 'Estado'?’. Platón, República, 369b-c. 
una pedagogía política que insufle alma a las leyes de la polis, convirtiéndolas en principio interno y ethos de la comunidad ${ }^{2}$.

Ahora bien, entre las formas de excelencia que animan la vida comunitaria en la ciudad platónica, el entendimiento racional está llamado a coronar la dirección de los asuntos colectivos, ya que nos permite acceder al conocimiento verdadero; y es que la unificación de lo múltiple y la armonización del conjunto de la comunidad política solo se realizan efectivamente en virtud de la aprehensión de la potencia del arje, que permite dar razón de todos aquellos asuntos que participan del principio de la polis. De ahí la importancia de que se logre cierta comunidad entre la cabeza de la polis y el entendimiento racional, de modo que gobiernen los que saben, esto es, quienes disponen del conocimiento de lo excelente y de la unidad perfecta que habrían de orientar la vida de la polis ${ }^{3}$. En suma, para la arquipolítica platónica, la fundación de la polis coincide con el acceso al fundamento y con la realización del principio interior de la comunidad política, por lo que la autoridad corresponderá siempre a quienes dispongan del conocimiento verdadero del arje de la polis.

2 Rancière (1996), pp. 90-91. En Las leyes, Platón introduce la igualdad geométrica como la más excelente y auténtica, toda vez que resulta desigual tratar de modo igual a los desiguales; así, la igualdad proporcional sería más justa: “Otorga, en efecto, más al que es mayor y menos al que es menos, dando a cada uno lo adecuado a su naturaleza; y también en cuanto a distinciones, concediéndoselas siempre mayores a los más excelentes en punto a virtud y al contrario a los que son de manera distinta por lo que toca a virtud y educación, distribuye proporcionalmente lo conveniente para cada cual”. Me remito a Platón, Leyes, 757c. Sin embargo, Platón también concede que, a veces, por ser indulgente con la mayoría y preservar la armonía social, no queda otra opción que someter a torsión la justa proporción y apostar por la igualdad simple y azarosa del sorteo democrático (Ibíd., 757d-e).

3 Así se explica que (de modo casi tautológico), en la "filosofía política" de Platón, los gobernantes ideales resulten ser los filósofos: "Pues bien; convenid entonces que lo dicho sobre el Estado y su constitución política no son en absoluto castillos en el aire, sino cosas difíciles pero posibles de un modo que no es otro que el mencionado: cuando en el Estado lleguen a ser gobernantes los verdaderos filósofos, sean muchos o uno solo, que, desdeñando los honores actuales por tenerlos por indignos de hombres libres y de ningún valor, valoren más lo recto y los honores que de él provienen, considerando que lo justo es la cosa suprema y más necesaria, sirviendo y acrecentando la cual han de organizar su propio Estado" (República, 540d-e). Y, si no se hacen cargo directamente de la dirección política como filósofos-gobernantes, quienes saben, es decir, los que conocen la razón de ser y el bien de los asuntos de la polis, se erigen como el más alto consejo de la ciudad ideal, su "consejo nocturno". Me remito a Leyes, 968a-969c. 


\section{El arte político, la métrica y la nomotética}

Ahora bien, ¿resulta sostenible el esquema de una arquipolítica? ¿Es posible neutralizar la contingencia de nuestras interacciones políticas, así como el trasfondo litigioso de la trama público-polémica, recurriendo al expediente de cierta filosofía política que consiste, en el fondo, en una política del fundamento, la cual fuerza la alternativa entre el modelo ideal y el acontecimiento político perecedero? ¿No habrá, acaso, que concluir que el régimen ideal de lo uno resulta inaccesible y, por tanto, no deberíamos asumir que, en vez de hacernos patente la interioridad del arje, la política platónica nos sitúa ante una ficción no demasiado coherente y sembrada de aporías?

Desde luego, si existe un escenario idóneo para poner de manifiesto las aporías de la política del fundamento, éste es precisamente el que encontramos en el Político platónico, uno de los sutiles diálogos del período crítico del filósofo (junto al Parménides, el Teeteto y el Sofista). Podemos adelantar -siguiendo a Castoriadis- que, en este nuevo escenario crítico, se va a problematizar cierta pretensión de fundar epistémicamente el régimen de lo uno, que haría del gobernante-filósofo el conductor óptimo de los asuntos humanos en una ciudad ideal; no en vano, en el Político, topamos con una auténtica "filosofía de la mixtura" (esto es, de lo posible, de lo relativo y de la aproximación), la cual asume que no es posible concebir la reglamentación perfecta de los asuntos humanos en algún ordenamiento político que actualice el arje como unidad interna de la comunidad (Castoriadis 2005, pp. 38-39). Así, pues, Platón problematiza en el Político todas las implicaciones aporéticas que se siguen del intento de concebir el ideal de una ciudad perfecta o de la ambición de fundar unívocamente la medida y orden correctos de toda la trama de los asuntos humanos que se despliega contingentemente en la polis (Ibíd., pp. 55-53).

Ya la puesta en escena del diálogo revela -como Stanley Rosen nos recuerda- un nuevo derrotero en el discurso político platónico: en otros diálogos platónicos es Sócrates quien, inmerso en la tensión erótica de la búsqueda del conocimiento verdadero de la vida buena, está encargado de interrogar continuamente a sus conciudadanos, a través de un diálogo inagotable sobre su manera de conducirse en la vida; sin embargo, en el Político, un extranjero proveniente de Elea se limita prácticamente a monologar, al margen del juego erótico del discurso, en una exhibición técnica de pericia dialéctica que está destinada a atribuirle cierto conocimiento experto al conductor político (Rosen 1995, pp. 2-3). En todo caso, el énfasis del extranjero de Elea en la tejne política y sus expectativas técnicas darán paso progresivamente a una reducción al absurdo de los intentos de hacerse cargo de los asuntos humanos a partir de algún conocimiento experto o tejne conceptual exclusiva (p. 7). Por si fuera poco, el Político sigue el camino del parricidio intelectual, toda vez que el extranjero parece anticipar y refrendar ambiguamente el juicio a Sócrates; no en vano, el eleata plantea cierta acusación dirigida contra aquellos que, como en el caso del propio Sócrates, no teniendo conocimiento experto de la tejne política, se atribuyen determinado arte político genuino, presuntamente ejercido en la interrogación dialógica de sus conciudadanos, de manera que incluso se atreven a cuestionar la sabiduría implícita en las 
prácticas e instituciones compartidas (Rosen 1995, p. 6) ${ }^{4}$. He ahí la broma platónica que nos conducirá a confrontar las pretensiones epistémicas del eleata con el sutil eros dialógico de Sócrates, en un juego discursivo que pone de manifiesto la compleja relación existente entre conocimiento y práctica (pp. 4 y 8).

Sin duda, en los diálogos socráticos, el arte político se perfila como una ciencia o tejne que no puede ser enseñada de cualquier manera, y que se asocia al conocimiento del bien; pero, ¿cómo entiende el extranjero esa ciencia o conocimiento experto de la política, que le atribuye al estadista? En el Político, la definición del estadista pasa, de hecho, por considerar el arte real de la política como una ciencia (episteme) de carácter cognoscitivo (gnostike), y no práctico-productivo (praktike); por otra parte, consiste en una ciencia directiva o prescriptiva (epitaktike), a diferencia de aquel saber meramente crítico (kritike), que se limita a juzgar sin implicarse en lo conocido (Platón, Político, 258d-260c). Además, el arte directivo de la política se perfila como un saber "soberano" y autodirectivo, pues no se restringe a la mera transmisión de directivas externas, tal y como haría un heraldo (Político, 260d-e).

Lo cierto es que esta ciencia "real", el conocimiento político o la administración soberana de los asuntos de la ciudad, exhibe un aspecto profundamente problemático. Por una parte -como Rosen sostiene-, nos genera complicaciones el nexo que, en la vida política efectiva, se establece entre conocimiento y experiencia práctica en el gobierno de los asuntos ciudadanos, así como el vínculo entre saber adecuadamente y prescribir autónomamente a los ciudadanos libres (Rosen 1995, pp. 116-117). Y es que, al no haber distinguido entre acción (praxis) y producción (poiesis), Platón se ve obligado a asimilar lo práctico y lo productivo, contraponiéndolos en bloque al saber cognoscitivo, de manera que la política termina siendo concebida dentro del ámbito cognoscitivo; pero, cuando se trata de ilustrar el arte político, curiosamente se recurre a actividades productivas, como el tejido (pp. 20-21). Por si fuera poco, a la hora de constituir un ordenamiento racional de nuestra vida compartida, el conocimiento eidético de la estructura ontológica no resuelve el problema; de ahí que la contemplación filosófica del orden inteligible no coincida totalmente con el arte político (pp. 45-46).

Además, -como plantea Castoriadis (2005, pp. 166-168)- la episteme que hace posible la correcta ordenación de la polis debería consistir en un saber total y abarcador, capaz de dirigir a todas las demás artes específicas, decidiendo en qué momento y condiciones han de intervenir ${ }^{5}$; sin embargo, cuando de lo que se trata es

4 De hecho, el extranjero sostiene que, si lo segundo mejor en la conducción de la polis son las buenas leyes surgidas de la experiencia cívica y del consejo ciudadano, entonces quien persuada a sus conciudadanos, poniéndolos contra las instituciones establecidas, ha de ser castigado como un mal mayor para la ciudad. Véase Platón, Político, 288e, 299c y 300ac.

$5 \quad$ En palabras de Platón: "Porque la ciencia que es verdaderamente real no debe actuar por sí misma, sino gobernar a las que tienen la capacidad de actuar, ya que ella, en lo que toca 
de hacerse cargo de las situaciones singulares y concretas, parece inviable una ciencia de lo universal que constituya un saber del eidos. Así, pues, resulta complicado que alguien pueda disponer de esta episteme absoluta que, por más que parezca inaccesible (pues lo más excelso no resulta discursivamente demostrable), operaría como arte soberano que dirige a las restantes actividades, y, además, serviría como parámetro de los ordenamientos políticos reales. Y es que, incluso en el caso de que cierto político epistemon dispusiera de un saber real semejante, ¿cómo podría resultar reconocido y ser voluntariamente obedecido por los conciudadanos, si éstos no tuvieran algún acceso al entendimiento de ese excepcional saber que nos permite aprehender el orden más adecuado, y no pudieran ser persuadidos racionalmente? (Castoriadis 2005, pp. 174-176). En suma, -podríamos concluir, siguiendo a Castoriadis (pp. 176-177)- no parece que la intelección eidética, tal y como la cultiva el filósofo, baste para hacerse cargo de gobernar y ordenar los asuntos de la polis; nos alejamos, así, del régimen ideal de una república de los sabios.

Así como, en el Sofista, el momento escandaloso consistía en la admisión del no-ser (de manera que la diferencia de los géneros supremos resquebrajaba la unidad inmóvil de lo inteligible), en el Político, se nos invita a consumar una nueva ruptura crítica: el extranjero de Elea considera indispensable que revisemos nuestras nociones sobre el arte de la medida (metretike), tanto para sostener la existencia del político, como para garantizar la posesión de una ciencia de las acciones ${ }^{6}$. Se trata de asumir que, además de la conmensurabilidad aritmética, la cual nos permite llevar a cabo la medición relativa del más y el menos, hay que tomar en cuenta otro modo de medir inherente a las artes humanas: la medida justa en relación con el justo medio, o sea, con lo oportuno, conveniente y debido (Político, 283d-284e). Pero, ¿hasta qué punto resulta crítica esta admisión de que el arte de medir, del cual participa toda tejne, concierne también a la determinación del justo medio?

Desde luego, la tejne metretike, esa ciencia que nos permite calcular tanto el exceso y la inferioridad, como la igualdad conmensurable, ocupaba un lugar crucial en diálogos socráticos como el Protágoras: no en vano, el arte de la medida aporta el conocimiento que nos permite una adecuada orientación en los asuntos humanos

a la oportunidad o inoportunidad, conoce el punto de partida y la puesta en marcha de los más importantes asuntos de la ciudad, mientras que las demás deben hacer lo que les ha sido impuesto" (Político, 305d).

$6 \quad$ Sostiene el extranjero de Elea: "Entonces, así como en nuestro examen del sofista nos vimos forzados a admitir que lo que no es es, puesto que en eso nos hizo refugiarnos el razonamiento, ¿así también ahora nos veremos forzados a admitir que el más y el menos son mensurables, no sólo en su relación recíproca, sino también en relación con la realización del justo medio? Porque, si eso no se admite, no será posible sostener, sin lugar a dudas, que exista el político ni ningún otro individuo de los que poseen una ciencia relativa a las acciones" (Platón, Politico, 284b-c). 
(cuando se trata, por ejemplo, de la recta elección de placeres y dolores) ${ }^{7}$. Sin embargo, en el Político el arte de la medida se torna más complejo, pues ya no contempla únicamente la medida aritmética, sino, además, una medida particularmente sujeta al marco intencional de referencia de nuestras actividades, así como a los propósitos humanos: el justo medio. En ese sentido, podemos señalar -con Castoriadis-que, del mismo modo que hay una medida relativa que nos permite determinar el más y el menos, existe también una medida absoluta, la medida justa inherente a cada actividad y que norma la oportunidad de cada producción humana (Castoriadis 2005, pp. 108-109). O bien, cabe añadir -siguiendo a Rosen (1995, pp. 120-121)- otras diferencias como que, en la medida aritmética, solo existen dos términos en oposición (en términos generales, lo correcto y lo incorrecto, siempre relativamente a una medida escalar), en tanto que la medida no aritmética contempla tres determinaciones (exceso, deficiencia y justo medio), que no se miden respecto a una magnitud escalar única. Además -señala Rosen (pp. 121-124)-, a pesar de la relatividad del patrón de medida aritmética, las magnitudes escalares que determinamos aritméticamente operan por sí mismas de un modo estipulado, mientras que, en la medida no aritmética, todo depende del propósito humano y del marco intencional de referencia que nos permite estimar el justo medio. Así, pues, se nos suscita cierto problema relativo a la conmensurabilidad, con todo lo que ello acarrea, ya que, sin cierta medida, resulta inconcebible la adecuada ordenación y dirección de los asuntos humanos: el arte de medir que es propio de aquellas artes susceptibles de medición aritmética (las cuales pueden establecer relaciones escalares y equivalencias conmensurables) resulta inconmensurable con el arte métrico de esas otras artes que se refieren al justo medio, o sea, a lo conveniente, lo oportuno o lo debido ${ }^{8}$ ¿ ¿No será que cada arte exhibe una forma de mesura inherente, la cual determina precisamente su especificidad? Y, en ese caso, ¿cómo podríamos determinar la justa medida de la orthe politeia, dada la inconmensurabilidad de las artes de medida?

En el Político, el extranjero de Elea parece tener muy claro que el recto gobierno solo puede ejercerse si se posee esa ciencia real que solo unos pocos poseen;

7 Véase Platón, Protágoras, 356d-357d. Sócrates introduce una ciencia métrica centrada en la medida aritmética del más y el menos: "¿Y si en la elección entre lo par y lo impar estribase la salvación de nuestra vida, cuando fuera preciso elegir correctamente, el más o el menos, en comparación mutua o en otros respectos, tanto si es de lejos como si es de cerca, qué nos salvaría la vida? ¿No sería el conocimiento científico? ¿Y no sería una cierta ciencia métrica, puesto que es la ciencia del exceso y de la inferioridad? ¿Porque acaso la ciencia de lo par y de lo impar va a ser otra que la aritmética?” (Protágoras, 356e357a).

$8 \quad$ Según el extranjero de Elea: "Está claro que podríamos dividir el arte de medir, como dijimos, cortándolo en dos del siguiente modo: ubiquemos en una de sus porciones a todas aquellas artes que miden en relación con sus opuestos un número, una longitud, una profundidad, un ancho, una velocidad; y, en la otra, a las que miden en relación con el justo medio, es decir, con lo conveniente, lo oportuno, lo debido y, en general, todo aquello que se halla situado en el medio, alejado de los extremos" (Platón, Político, 284e). 
de hecho, entre los diversos regímenes políticos, el único correcto por excelencia es aquel en el cual el político epistemon dirige los asuntos humanos (Político, 293a-c). Y todos los otros regímenes (monarquía, tiranía, aristocracia, oligarquía y democracia) no son sino imitaciones del más perfecto régimen, ése instituido por el arte real: en unos casos, se trata de imitaciones decentes, si es que la polis está regida por buenas leyes (como ocurre en la monarquía, la aristocracia o la democracia, legalmente gobernadas), y, en caso de que carezcan de leyes adecuadas, estamos ante pésimas imitaciones del arte político, o sea, ante los peores regímenes, como la democracia sin ley, la oligarquía y la tiranía (Político, 293d-e y 301a-303c).

Ahora bien, aunque el arte legislativo (nomothetike) compete a la tejne política, esto no significa que el gobierno de las leyes sea lo más excelente ${ }^{9}$. Y es que las leyes devienen letra muerta (grammata inertes) ante la variabilidad y contingencia de los asuntos humanos. En ese sentido, la generalidad abstracta, así como la inflexibilidad de la ley, no permiten prescribir lo más justo, lo mejor y más perfecto; además, las leyes permanecen mudas ante los cambios circunstanciales: no asisten con inteligencia el desenvolvimiento concreto de los asuntos humanos, ni permiten la revisión de la adecuación del ordenamiento político según la situación ${ }^{10}$. No obstante, por más que los códigos legales parezcan grammata muertas que repiten de modo inflexible lo mismo, sería aún peor oponerse (por ignorancia e interés) a las leyes instituidas, máxime cuando éstas constituyen un resultado de la experiencia acumulada y de la deliberación sensata compartida en los consejos del demos (Político, 300b).

Así, pues, -para el extranjero de Elea- la institución de buenas leyes es un mal menor, a falta del político real; no en vano, la crítica del eleata a la ley se inscribe en esa "filosofía de la mixtura" que corresponde a los diálogos platónicos de madurez: por una parte, la ley no consigue responder a la diferencia y contingencia de las prácticas humanas; pero, a su vez, constituye el remedio, la segunda mejor opción, para hacerse cargo de la fragilidad de la polis, cuyos ordenamientos, tradiciones e instituciones siempre están expuestos a la posibilidad de la desintegración ${ }^{11}$. Tal vez,

$9 \quad$ En palabras del eleata: "En cierto modo, es evidente que la función legislativa compete al arte real; lo mejor, sin embargo, es que imperen, no las leyes, sino el hombre real dotado de sensatez" (Politico, 294a).

$10 \quad$ Sostiene el extranjero de Elea: “Que la ley jamás podría abarcar con exactitud lo mejor y más justo para todos a un tiempo y prescribir así lo más útil para todos. Porque las desemejanzas que existen entre los hombres, así como entre sus acciones, y el hecho de que jamás ningún asunto humano - podría decirse - se está quieto, impiden que un arte, cualquiera que sea, revele en ningún asunto nada que sea simple y valga en todos los casos y en todo tiempo" (Político, 294b).

11 En palabras del eleata: "Pero, ahora que no hay aún -como, por cierto, decimos- rey que nazca en las ciudades como el que surge en las colmenas, un único individuo que sea, sin más, superior en cuerpo y alma, se hace preciso que, reunidos en asamblea, redactemos códigos escritos, según parece, siguiendo las huellas del régimen político más genuino" (Político, 301e). 
podríamos argumentar-siguiendo a Castoriadis (2005, p. 181)- que, si las leyes surgen de la aceptación pública del buen consejo progresivo al alero de las tradiciones sensatas, entonces estaríamos situando en el centro de la constitución de la polis la autolegislación permanente del demos, así como la autoinstitución permanente de la sociedad; pero se trata de una interpretación del Político demasiado optimista, que no concuerda con la marcada desconfianza de Platón hacia la vida democrática, el peor de los regímenes legales, según el extranjero de Elea establece.

Recapitulemos. Lo mejor es el gobierno regio (arje basilike) del epistemon, quien dispone del arte político soberano que le permite decidir cuándo es oportuno y cómo es conveniente ejercer cada arte, teniendo siempre el justo medio como criterio; en ese sentido, el estadista idóneo, el hombre regio, se caracteriza por estar dotado de un saber real que corresponde a la más excelsa deliberación práctico-prudencial (phronesis) (Castoriadis 2005, p. 154). Pero, puesto que no hay posibilidad de que un hombre regio se haga cargo de todos y cada uno de los detalles de la polis, lo segundo mejor es el gobierno basado en el arte legislativo, del cual los códigos escritos constituyen únicamente inscripciones estáticas (Ibíd., pp. 178-179). Sin duda, lo mejor sería que el hombre regio gobernara en virtud de su excepcional phronesis, pero, en la medida en que resulta inviable la orthe politeia del estadista regio, entonces la ciudad epistémica -como plantea Rosen (1995, p. 167)-, es decir, el régimen de las leyes técnicamente correctas, se convierte en la segunda mejor opción. En ese sentido, podemos establecer -con Rosen (pp. 170-171)- que, así como la tejne política es solo una imitación del modelo regio de la phronesis, del mismo modo, las leyes constituyen únicamente simulacros de la tejne nomothetike que compete al arte político. De esa manera, se explica que, ante la imposibilidad de cumplimiento del paradigma de la phronesis real, el segundo mejor régimen pase a ser la monarquía gobernada por un rey epistémico, que gobierna con el arte de la legislación y se hace cargo del cumplimiento de las leyes (Ibíd., p. 176).

Podemos añadir, además, -siguiendo nuevamente a Rosen (p. 171)-que, pese a que el eleata comienza concibiendo el arte real como una forma de gnosis prescriptiva capaz de decidir lo mejor (al partir del conocimiento de lo noble, justo y bueno), sin embargo, termina ilustrando la política como una tejne que se ejerce en tanto que arte defensivo frente a las amenazas de la naturaleza, y básicamente orientado a la coordinación protectora de los cuerpos. Así, pues, la armonización de la polis deviene artefacto político, de la misma manera que el ciudadano se constituye no solo como simulacro del filósofo o como falsa imagen del hombre eminentemente racional, sino, también, en tanto que construcción de esa tejne política que combina los rasgos de carácter y entrelaza los elementos naturalmente discordantes (Ibíd., p. 70). En conclusión, si las leyes son solo un simulacro de la tejne, la cual constituye un simulacro de la phronesis, podemos afirmar -con Rosen (pp. 179 y 190)-que el arte de la política se aplica básicamente a través de simulacros; la política deviene, así, gestión de simulacros en el seno de una polis que se construye a través de las copias de copias: la ciudad de los simulacros. 


\section{Los simulacros de la polis}

A la hora de construir las imitaciones de la orthe politeia y gestionar la ciudad de los simulacros, se pone en circulación cierto discurso imitativo, particularmente relevante cuando se trata de persuadir a nuestros conciudadanos, para que se atengan al ordenamiento de la polis y se entrelacen en el tejido de la comunidad: el mito. No en vano, los mitos platónicos ejercen -como Luc Brisson (2005, pp. 112-113) plantea- una función curativa, al concretar cierto arte de encantamiento (epoide) o hechizo (kelesis), capaz de modificar el comportamiento físico y moral, devolviendo al alma humana el control de la razón y la sabiduría. No es de extrañar, entonces, que incluso Platón, el filósofo que pretende establecer el correcto ordenamiento de la polis, recurra al mito como medio pedagógico; eso sí, de un modo instrumental, que refuerza el carácter de simulacro en el mito, como se desprende del hecho de que el filósofo reglamente exhaustivamente la construcción y difusión de los relatos miméticos (Brisson 2005, p. 114).

Así, pues, el arte político también parece concernir a la producción y comunicación de mitos políticos, que encantan no solo debido a ese entusiasmo placentero que todo juego mimético suscita, sino también gracias al conjunto cerrado de sentido o a la clausura totalizadora que el relato mítico despliega (Brisson 2005, p. 116). En suma, en la ciudad de los simulacros, el mito resulta vital como medio de transmisión del saber tradicionalmente compartido a través de las generaciones; pero, además, los mitos platónicos aportan un crucial instrumento de persuasión y modelado ético-político, que concuerda con las exigencias de la construcción del ordenamiento político, garantizando la sumisión y conformidad de cuantos no son filósofos, o sea, de la mayoría de esos simulacros de seres racionales que son los conciudadanos (p. 164). Y es que en la política platónica -como Brisson sostiene- el mito sirve como relevo e instrumento del discurso filosófico (p. 158).

Pues bien, en el Político, el extranjero de Elea relata un mito específicamente político, por cuanto concierne a la caracterización del arte soberano de la política: el mito del reino de Cronos y de la alternancia de los ciclos cósmicos (268e-274d). Se trata de un mito construido, de un simulacro elaborado a partir de tres relatos tradicionales: el mito de Atreo y Tiestes, en el cual Zeus lleva a cabo una inversión en el curso de los astros; el mito del reino de Cronos, que es tanto como decir la imagen de una edad de oro, y, en tercer lugar, el mito de la autoctonía humana, esto es, el nacimiento de los hombres a partir de la tierra (269a-b). El extranjero de Elea presenta el mito como un juego prácticamente dirigido a orientar a los niños, pero, sin embargo, construye el relato como un marco de referencia para determinar el actual orden de las cosas, y reelabora todo un modelo del arte político, basándose en el mito político; concretamente, a través del mito del reinado de Cronos, resulta redescrito el paradigma del pastoreo real y la definición del arte político como ciencia de la crianza colectiva de los hombres (268d-e y 274e-c).

Si dejamos de lado los problemas de construcción e inconsistencias que este mito de síntesis exhibe, cabe sostener que, a grandes rasgos, tematiza la existencia un 
ciclo originario de las cosas, en el cual los dioses (bajo la dirección de Cronos) ejercen un pilotaje divino que se hace cargo de todo movimiento, por más que se trate de un extraño ciclo reverso, de manera que los hombres resurgen de la tierra ya ancianos, y vuelven a la infancia. En ese sentido, el reinado de Cronos corresponde a la autoctonía de una humanidad que disfruta del más solícito pastoreo divino y, por ende, de la más pródiga abundancia. En suma, el originario ciclo reverso, movido por los dioses y custodiado por Cronos, coincide no solo con la autoctonía humana, sino también con la áurea edad de la abundancia (271d-272b). Sin embargo, existe otro ciclo, el actual, en que el piloto divino descuida la dirección del movimiento cósmico, de manera que el cosmos, abandonado a sí mismo y a cargo de su propio curso, se precipita en la inercia natural, y despliega la mezcolanza y corrupción que resultan connaturales a su constitución material; consiguientemente, todo cae en el curso habitual que nos lleva del nacimiento a la muerte, y todo resulta naturalmente alterado, tal y como ahora lo experimentamos $(272 \mathrm{e}-274 \mathrm{a})^{12}$. De ese modo, tras la catastrófica reversión del ciclo, la penuria y el desorden se adueñan de todas las cosas y, en el período actual, abruman a la existencia humana hasta tal punto, que los dioses les entregaron a los hombres ciertos dones y artes, indispensables para la preservación de la vida sobre la tierra; se trata de aquellos bienes civilizatorios que la humanidad habría de imitar en adelante, si pretende subsistir (como el fuego, las artes o la agricultura) (274b-d). Eso sí, curiosamente, el extranjero de Elea omite, de entre los dones divinos, el arte político, que, de acuerdo con el mito del Protágoras, habría sido muy bien repartido entre toda la humanidad, con el fin de que los hombres se reunieran pacíficamente, y las ciudades preservaran cierto orden y armonía (Protágoras, 320d-322e).

Ciertamente, -como el extranjero de Elea plantea-, el mito del reinado de Cronos se introduce en el diálogo con una finalidad pedagógica, y básicamente para revisar la definición del arte político como pastoreo del rebaño humano; y es que, en el ciclo político actual, en que el mundo humano sigue su propio curso, y cuando los políticos son seres humanos semejantes a los gobernados, ya no se podría ejercer ese constante y exhaustivo pastoreo, esa conducción y cuidado perfectos, que solo un pastor divino lograría (Político, 274e-275d). Pero, sin duda, este auténtico simulacro de mito lleva a cabo algo más, a saber: la construcción de un imaginario político

12 En el fondo, el mito del reinado de Cronos establece una alternancia entre dos ciclos, que se suceden tras lapsos catastróficos: el ciclo del pilotaje divino, del movimiento circular retrógrado, de la autoctonía y de la abundancia, por una parte, y, por otra, el período actual, el del curso habitual de la naturaleza material, el de la existencia mortal y la escasez. En palabras del extranjero de Elea: "En lo que toca a éste, nuestro universo, durante un cierto tiempo dios personalmente guía su marcha y conduce su revolución circular, mientras que, en otros momentos, lo deja librado a sí mismo, cuando sus revoluciones han alcanzado ya la medida de la duración que les corresponde; y es entonces cuando él vuelve a girar, espontáneamente, en sentido contrario, porque es un ser viviente y ha recibido desde el comienzo una inteligencia que le fuera concedida por aquel que lo compuso" (Político, 269c-d). 
perfectamente instrumental para la preservación de la armonía de la polis. Y si este mito de síntesis, copia de varios relatos miméticos, resulta funcional y eficaz, es sobre todo por su exquisita ambigüedad, tan pródiga en sentidos: no solo plantea el mitema de un ciclo necesario de lo que hay, aunque, en este caso, a través del relato de la alternancia de los ciclos cósmicos; además, introduce el mitema de la autoctonía que naturaliza la jerarquía de funciones en la polis, y hermana a los hombres como hijos de la tierra; por último, incorpora el mitema de la edad de la abundancia, que nos seduce con la perspectiva de la ausencia de necesidades debido a la infinita prodigalidad divina.

Por si fuera poco, el simulacro de mito que Platón construye exhibe el reverso de la situación míticamente consagrada, al presentarnos el mitema político de que, habiendo concluido el pastoreo divino de Cronos y la edad de oro de nuestra autoctonía, solo nos queda el arte político, es decir, el cuidado, la armonización y el entrelazamiento de los cuerpos comunitarios, si es que queremos preservar la vida de los hombres y la coexistencia en la polis. Si recordamos las virtudes persuasivas que Brisson le atribuye a los mitos platónicos, no cabe duda de que estamos ante una obra maestra en el arte de la construcción de simulacros políticos: un mito que encanta y hechiza, al atrapar al receptor en el juego de sus múltiples planos y sutiles alusiones; un simulacro que modela las almas, comprometiéndolas con la expectativa de una armonía protectora siempre recuperable, toda vez que los hombres se amolden a los órdenes políticos que humanamente podemos construir. Se trata del mito fundacional de una tejne política que sustituiría al divino gobierno de la mítica edad de oro de Cronos; pero, además, es una construcción mítica que totaliza el sentido en segundo grado, pues también confiere significado a la destotalización y desorden del curso actual de los asuntos humanos. En suma, estamos ante el mito político que consagra la ciudad de los simulacros.

En el contexto del Político, no parece muy creíble esa afirmación del extranjero de Elea según la cual, lo que está en juego en la discusión sobre el arte político es, más que nada, la adquisición de pericia dialéctica (285d). Pero, ¿acaso carece totalmente de consistencia esta reivindicación del juego dialéctico como centro del diálogo? Desde luego, si consideramos que la tejne dialéctica pasa únicamente por el análisis conceptual de la articulación eidética de las cosas en general (y de lo político, en este caso), entonces, podemos afirmar que el arte dialéctico de la división eidética experimenta una rotunda reducción al absurdo en el Político, dada la magnitud de los desvaríos y arbitrariedades en que se incurre al definir conceptualmente el arte político ${ }^{13}$. Ahora

13 Recordemos la errática definición del arte político que formula el extranjero de Elea, en la cual se introducen divisiones que tan pronto se refieren a la ciencia del político, como al objeto gobernado; por si fuera poco, en la articulación eidética del arte político figuran géneros tan "esenciales" como el ser pedestre, no tener cuernos, ser bípedo, implume... En palabras del extranjero: "De la ciencia cognoscitiva, en efecto, habíamos hallado, para empezar, una parte directiva. A una de sus porciones la llamamos, recurriendo a una comparación, 'autodirectiva'. A su vez, de la ciencia autodirectiva habíamos desgajado como 
bien, si tomamos en cuenta que el juego dialéctico, en que el extranjero pretende adiestrarnos, parece incluir también la construcción de relatos imitativos persuasivos y la generación de paradigmas creíbles, entonces cabría sostener que el eleata no nos engaña; no en vano, lo que está en juego en el diálogo del Político es precisamente la construcción de algunos simulacros de cierta conducción divina y de una phronesis soberana (ambos tan excelsos, que el hombre no los puede aplicar, sino solo imitar).

No llegaremos tan lejos como Castoriadis, quien considera que el mito del reino de Cronos no fue introducido en el diálogo con el fin de revisar la definición del político como pastor del rebaño humano, sino que, más bien la definición del arte político como pastoreo habría sido formulada -sostiene Castoriadis (2005, pp. 61 y 123)- como un artificio retórico, para así poder presentar el relato mítico y, de ese modo, consagrar la heteronomía del sentido del arte político (su sujeción al significante mítico-teológico). Pero sí observamos -con Rosen (1995, p. 39)- que, en el Político, el mito opera como una elaboración y purificación del logos, extraviado en confusas distinciones eidéticas. Por cierto, también los paradigmas contribuyen al despliegue del logos en el diálogo del Político; no en vano, sin la aprehensión de la semejanza en la alteridad, y sin poder captar semejanzas parciales en instancias diferentes, difícilmente podría concebirse el desarrollo del logos. En ese sentido, las distinciones eidéticas y los análisis conceptuales del Político dependen -como sugiere Rosen (1995, p. 111) - de la intuición de ciertas analogías y, por ende, de la percepción de lo semejante en lo diferente.

Pero, ¿a qué despliegue del logos corresponden concretamente los paradigmas del Político? Aparentemente, oscilan entre la ejemplificación y la creación de semejanzas por medio de analogías; o, si lo planteamos en términos de tropos discursivos, los paradigmas se aproximan ora a la metonimia, ora a la metáfora ${ }^{14}$. Sea como sea, el mismo logos discursivo que no duda en recurrir a la construcción de imitaciones verosímiles para tornar inteligibles los simulacros de la polis, tampoco parece tener demasiados problemas a la hora de sustituir la pura intelección eidética, reemplazándola por

uno de sus géneros y no, por cierto, el más pequeño, la crianza de seres vivos. De la ciencia de criar seres vivos, una especie es la crianza de rebaños, y de la crianza en rebaños, por su lado, una especie es el apacentamiento de pedestres. Del apacentamiento de pedestres quedó bien seccionada el arte de criar una raza sin cuernos. De ésta, a su vez, la parte que hay que separar debe hallarse atando no menos de tres cabos, caso de que se la quiera reunir en un solo nombre, denominándola 'ciencia de apacentar una raza que no admite cruce'. Finalmente, el segmento que se separa de ésta, el arte de apacentar hombres, única parte que resta en el rebaño bípedo, es ésta la que estábamos buscando, a la que se ha llamado 'real' y, simultáneamente 'política'” (Político, 267a-c).

14 El extranjero de Elea caracteriza los paradigmas en los siguientes términos: "Por lo tanto, ¿comprendes bien ahora que un modelo se forja, precisamente, cuando una misma cosa que se halla en otra cosa diferente y aislada de la primera es objeto de una opinión acertada y, al ser comparada, da nacimiento a una única opinión verdadera sobre una cosa y la otra juntas?" (Político 278c). 
la aprehensión de parecidos de familia parciales. Parece que, en los asuntos humanos, la forma en sí del modelo eidético se ve suplantada por los tropos paradigmáticos, los cuales configuran esa red de simulacros que constituyen la ciudad. De modo significativo, los paradigmas que Platón suele escoger, cuando se trata de caracterizar el arte político, conciernen habitualmente a alguna tejne; como si el ordenamiento de la vida compartida consistiera en la aplicación de cierto conocimiento experto, destinado a la defensa de los hombres frente a los riegos naturales, mediante la disposición armónica de los cuerpos. Se cierra, así, el círculo de cierto "constructivismo" platónico (Rosen 1995, p. 16): el arte de construcción de los simulacros apropiados, que concierne al hombre político, converge con la elaboración del mito de una tejne capaz de regular todos los asuntos de la polis.

De partida, cuesta creer que la caracterización del estadista como un pastor del rebaño humano constituya una definición formal, resultado del análisis conceptual y de la división eidética; se trata, más bien, de un cierto paradigma sostenido por una intuición analógica, cuya interpretación será enriquecida mediante la interpretación del relato imitativo de un mito. No es -como Castoriadis cree- que la definición del arte político sea un artificio retórico y un pretexto formal para presentar el mito del reinado de Cronos. En el diálogo, ya se presupone una intuición analógica del arte político y, a partir de ella, se desarrolla un análisis conceptual, el cual será ulteriormente revisado con los matices interpretativos que el mito aporta; de esa manera, la primera intuición analógica resultará luego redescrita en un segundo paradigma. No en vano, el extranjero de Elea aclara que la introducción del mito permite percibir con más nitidez a aquel que, por analogía con el "modelo" del pastor, se hace cargo de la conducción y cuidado de los hombres, y añade que el pastor divino no admite "parangón" con los gobernantes actuales, pues éstos son demasiado "semejantes" a sus gobernados (Político, 275b).

Pero, ¿cuáles son la intuición analógica y las semejanzas estructurales que sostienen el paradigma del pastoreo, cuando se trata de concebir lo propio del arte político? Aparentemente, la semejanza en la diferencia, que cabe aprehender entre política y pastoreo, consiste en que ambas artes conciernen a la crianza y cuidado colectivos de un rebaño (Político, 267d). Curiosamente, la metáfora del rebaño resulta bastante extraña en la reflexión política griega -como nos recuerda Foucault (1996, p. 99)-, aunque estaba muy difundida en las sociedades orientales antiguas; pero, sin duda, en el Político, la comparación del arte político con el pastoreo ocupa un lugar central en la discusión.

¿Podemos decir que en Platón se halla una consagración del paradigma pastoral de la política? Sabemos por Foucault (1996, pp. 100-101) lo que el paradigma del poder pastoral involucra: se supone que el pastor ejerce su poder sobre un rebaño (más que sobre un territorio o unos dominios), y se asume que el pastor ha de reunir, cuidar y conducir a su grey, de manera que se asegure la salvación de todos y cada uno de los individuos, haciendo todo lo posible por el bien de su congregación. Y es que -como el extranjero de Elea plantea en el Político (268a-b) - un pastor se hace cargo de todos los aspectos que conciernen a su rebaño: cría y alimenta a la manada; es el médico que cuida a los individuos enfermos; concierta los agrupamientos y organiza 
la reproducción; amansa y armoniza al rebaño con música y juegos. No cabe duda de que este paradigma del poder pastoral resultó central para el primitivo pastorado cristiano, e incluso podríamos preguntarnos si -como sugiere Sloterdijk (2000, p. 83)-el programa político de la moderna sociedad humanista, o sea la antropotécnica de gran escala, no estará acaso prefigurado de modo muy imaginativo en el diálogo platónico. Aparentemente, la tejne de un político definido como "pastor" consistiría -según Sloterdijk - en una antropotécnica soberana, la cual no solo dispondría la crianza, selección y domesticación del rebaño humano, sino que, además, modelaría el carácter de los especímenes y, cuando fuera preciso, excluiría del zoológico humano las naturalezas inadecuadas (Ibíd. pp. 80-82).

Sin embargo, no podemos olvidar que, en el diálogo platónico, el modelo del poder pastoral es desechado. No solo establece -como nos recuerda el eleata- una definición demasiado amplia del arte real, abarcando una gama demasiado amplia de oficios (relativos a la conducción, cuidado, crianza y entretenimiento), de manera que, entonces, el médico, el pedagogo, el músico, entre otros, le disputarían al político sus funciones (Político, 267e-268c). Además, en el gobierno político no se cumple esa diferencia esencial entre el pastor y su rebaño, que es consustancial al pastoreo humano del ganado: como ya no parece que pueda darse la conducción de un pastor divino $^{15}$, -según el extranjero de Elea- topamos con el hecho de que los gobernantes actuales no son muy diferentes en cultura y educación de aquellos a quienes dirigen (275b). Por si fuera poco, un pastor responde por cada animal del rebaño, pero es humanamente imposible que el político se siente a la cabecera de cada uno de los ciudadanos, para cuidar abnegadamente de todas sus preocupaciones y necesidades (295b). En ese sentido, parece tener razón Foucault cuando observa que, en Platón, no se consagra un poder pastoral que haya de hacerse cargo de salvaguardar la vida de todos los individuos de su rebaño; más bien, el problema que se plantea en el Político sería -para Foucault (1996, p. 110)- el de la relación entre unidad y multiplicidad, o sea el entrelazamiento armónico de los diferentes elementos constituyentes, tanto en la polis como en el ciudadano.

No obstante, la insistencia platónica a la hora de comparar la política con alguna forma de tejne (la cual disponga y armonice los cuerpos en una ciudad que se defiende de la naturaleza), da para pensar que, en última instancia, la búsqueda del arje de la política, así como el régimen de armonización de la comunidad desde su principio interno, se reducen finalmente a la construcción de simulacros, para regular la crianza, selección y domesticación del zoológico humano. Así ocurre con el paradigma del pilotaje, el cual, en varios diálogos platónicos (entre ellos, el Político),

15 De modo significativo, cuando tenía lugar el pastoreo divino en el reinado de Cronos, no había política: “(...) un dios los apacentaba dirigiéndolos personalmente, como ahora los hombres, que son una especie viviente más divina, apacientan a otras razas que le son inferiores. Cuando el dios los apacentaba, no había regímenes políticos (...)" (Político, 271e). 
permite comparar la conducción política del Estado con ese arte de la navegación que hace posible dirigir a la tripulación, hacer frente a los peligros del océano $\mathrm{y}$, de ese modo, llegar a buen puerto ${ }^{16}$. Habitualmente, Platón recurre al paradigma del pilotaje, para recordarnos que la conducción de la ciudad (como la navegación en alta mar) requiere de una tejne específica y de un conocimiento experto, que solo unos pocos tienen, de manera que resulta inconcebible dejar en manos de la muchedumbre las decisiones que competen al estadista ${ }^{17}$. Pero el paradigma del pilotaje tiene más implicaciones; y es que, así como parecería absurdo creer que ciertas reglas codificadas, que estén consensuadas por la muchedumbre y fijadas por escrito, puedan suplantar la destreza del piloto a la hora de afrontar las contingencias de la situación, lo mismo corre para el gobierno político: la genuina ciencia política trasciende la inercia de las normas instituidas ${ }^{18}$.

Por cierto, está de más recordar el éxito que ha tenido el paradigma del pilotaje, así como la comparación de la gestión del Estado con la navegación, no solo en la moderna reflexión política y en la construcción de la Razón de Estado por parte de la ciencia de la administración política, sino, también, en los contemporáneos enfoques sistémicos, que directamente reducen la política a formas de control cibernético, esto es, a pilotaje organizacional. Nuevamente, Platón se muestra de lo más imaginativo cuando se trata de forjar los paradigmas que habrían de ocupar un lugar central en el imaginario político occidental, y, sobre todo, brilla cuando está en juego la construcción de ese simulacro tan persuasivo que es el mito de la tejne política.

Si hay una tejne que, en los diálogos platónicos, se presenta recurrentemente como paradigma para la política, ésta es la medicina, ese arte de cuidar, purificar y sanar los cuerpos, ya sea sajando partes del cuerpo o cauterizando, ya sea prescribiendo dietas o purgando, ya sea indicando tratamientos con fármacos ${ }^{19}$. Y es que -como nos recuerda frecuentemente Platón-el arte político también consiste en

16 Una de las más notables presentaciones de este imaginativo paradigma del pilotaje náutico la encontramos en Platón, República, 488a-e.

17 Refiriéndose a la estabilidad que procuran las ciudades, por medio de la imitación del régimen político más genuino, sostiene el extranjero de Elea: "Y claro que hay muchas [ciudades] también que, en una u otra ocasión, como naves que se van a pique, perecen, han perecido y aún perecerán a causa de la iniquidad de aquellos pilotos y navegantes que de las cosas de mayor importancia tienen la mayor ignorancia y que, sin poseer el menor conocimiento de los asuntos políticos, se figuran tenerlo de modo pleno y mucho más claro que todas las ciencias" (Político, 302a).

18 En palabras del eleata: "Así como el piloto, procurando siempre el provecho de la nave y los navegantes, sin establecer normas escritas, sino haciendo de su arte ley, preserva la vida de quienes con él navegan, así, también, del mismo modo, ¿de quienes tienen la capacidad de ejercer de esta manera el gobierno, podría proceder el recto régimen político, ya que ellos ofrecen la fuerza de su arte, que es superior a la de las leyes?" (Político, 296e297a).

19 Platón introduce todo este repertorio de tratamientos médicos en República, 406d y 407c-d. 
el cuidado, purificación y saneamiento del organismo de la polis, ya que ésta siempre puede resultar afectada por dolencias varias; no en vano, el político ha de procurar constantemente la salud del cuerpo de la ciudad, toda vez que los Estados actuales parecen afiebrados y gravemente expuestos tanto a desórdenes internos como a la amenaza de invasiones externas ${ }^{20}$. Así, pues, el arte del estadista pretende restituir un régimen de vida adecuado, sin excesos que sobrepasen peligrosamente el límite de las necesidades básicas, y sin desórdenes ni interferencias en el funcionamiento de los órganos de la ciudad; se trata de salvaguardar la unidad interna del organismo político frente a los riesgos de intemperancia y contaminación, que convertirían a la polis en una presa fácil para la desintegración interna y las invasiones externas. Eso sí, la terapéutica que el Estado despliega es más preventiva y eficiente, que las traumáticas intervenciones de los médicos, esos superfluos tratamientos que disfrazan un régimen de vida enfermo (República, 404e-405a). No en vano, siempre resulta preferible mantener el cuerpo sano y llevar un régimen de vida armonioso, antes que tener que tratar médicamente los cuerpos irremediablemente enfermos, prescribiendo evacuaciones o pociones, incisiones o cauterizaciones; y es que la medicina, tanto del cuerpo como del organismo de la polis, ha de consistir preferentemente en el cuidado y ejercicio constantes, evitando los excesos de una aprensiva medicación corporal (407c-408b). De ahí que la medicina política de Platón reserve la atención médica a los ciudadanos con buena constitución física y anímica; se trata de una terapéutica basada en la selección de los bien constituidos, que condena a muerte o deja morir a los irremediablemente enfermos o a los naturalmente incurables (409e410a). Por cierto, como la metafórica del pilotaje, también el paradigma terapéutico permite sostener que el arte político constituye un conocimiento experto y exclusivo de unos pocos, que no tolera intromisiones de la muchedumbre, ni se deja reducir a la codificación de instrucciones o recetas ${ }^{21}$.

Ahora bien, frente al modelo del experto pilotaje, el paradigma terapéutico despliega una doble intuición analógica: por una parte, consagra la clausura y orden

El diagnóstico de la ciudad "afiebrada", alejada del verdadero Estado y de la polis sana, lo encontramos en República, 372e-373e.

21 En el Político, el extranjero de Elea pone de manifiesto, a través del paradigma de la medicina, la fascinación platónica por el mito de la tejne política, exclusiva de los que saben; así se explica la siguiente comparación entre el gobierno de quienes tienen la ciencia real y el arte de quienes disponen de la ciencia médica: "Estos hombres, gobiernen con la aceptación voluntaria de sus súbditos o sin ella, según códigos escritos o sin ellos, sean ricos o pobres, debemos considerar - tal como antes pensábamos- que ejercen su gobierno, cualquiera que sea, conforme a un arte. Otro tanto ocurre en el caso de los médicos: que nos curen con nuestro asentimiento o sin él, cortando, quemando o provocándonos algún otro sufrimiento, lo hagan según un código escrito o prescindiendo de él, sean pobres o ricos, en ningún caso vamos a dejar de llamarlos 'médicos', siempre que sus prescripciones respondan a un arte, $\mathrm{y}$, al purgarnos o reducir de algún otro modo nuestro peso o bien aumentarlo, lo hagan para bien de nuestro cuerpo, mejoren su estado y salven con sus tratamientos a los pacientes a su cuidado" (Político, 293a-b; véase, también, 295c-e). 
internos del organismo de la polis, pero, por otra parte, establece que la salud del cuerpo político solo puede salvaguardarse ante el riesgo de contagio y contaminación externa, mediante cierto fármaco ambiguo, o sea introyectando el mal en pequeñas dosis. No cuesta mucho asociar esta terapéutica platónica al paradigma inmunológico -como lo designa Roberto Esposito-, el cual, al privilegiar el léxico organológico, así como la metafórica de la enfermedad y la analogía del sistema inmunológico, no solo ha sido medular en la construcción imaginaria de un genuino organismo político moderno y en la organización de la biopolítica y del Estado terapéutico, sino, también, ha resultado crucial para la irrupción de cierta inmuno-política contemporánea, caracterizada por la neutralización aséptica, la exclusión alérgica y la autorreacción defensiva (cf. Esposito 2005, capítulos 4 y 5).

De hecho, el peso de la metáfora organológica es evidente en Platón, cada vez que compara la comunidad de la polis con un cuerpo internamente organizado para el cumplimiento de sus funciones orgánicas. No en vano, Platón retrata la ciudad (no menos que el mismo cosmos o el discurso) como un organismo viviente: se trata de una instancia internamente organizada y clausurada en virtud de su unidad y autosuficiencia, la cual está dotada de una piel que la separa del medio externo, y provista de un conjunto de órganos y miembros funcionalmente especializados, así como de una cabeza que lleva a cabo el gobierno anímico del conjunto ${ }^{22}$. Por ora parte, el paradigma terapéutico, mediante el cual Platón construye un sistema de metáforas para investir el arte político, prefigura no solo ciertas modalidades antropotécnicas de agrupamiento, selección y control poblacional, sino, también, formas de modelado e intervención en el alma y cuerpo individuales, que anticipan, de alguna manera, ese gobierno ejercido sobre la vida que es característico de la biopolítica contemporánea y de su ordenamiento inmunológico de la comunidad política. Y, por si fuera poco, la metáfora médica platónica ilustra adecuadamente el paradigma inmunológico -tal y como Esposito lo entiende-, en su sentido más propio, a saber: como instrumentalización positiva de lo negativo e inherencia del mal a su control terapéutico; en tanto que reproducción artificial de lo negativo e inoculación homeopática del agente patógeno, para inmunizar frente al contagio, pero, además, como desvío y neutralización del mal, por medio de su representación interna y englobamiento preliminar (Esposito 2005, pp. 18-23). En suma, el aporético procedimiento inmunitario que se perfila en la farmacopea política de Platón, en la medida en que solo consigue excluir lo negativo incluyéndolo, configura una modalidad privativa de comunidad política, que únicamente protege el principio interno de la polis, a través de la destitución y la representación artificial de un simulacro de comunidad (y de una manera tal, que potencialmente convierte el rechazo de lo otro y la conjuración del desorden, en síndrome autorreactivo y autointoxicación de sí mismo) (Ibíd., pp. 27 y 226-234).

22 Un vívido ejemplo de la metáfora organológica se encuentra en Platón, Leyes, 964e965a. 
Por cierto, todo este dispositivo inmunitario prefigurado en la terapéutica platónica parece girar en torno al juego ambiguo de ese pharmakon, simultáneamente remedio y tóxico, que Derrida analizó magistralmente. Y es que -como Derrida plantea- la reconstitución de la unidad de la ciudad, así como la preservación de su fuero interno, pasan, en la farmacopea platónica, por la inoculación de un representante del mal (un remedio/tóxico), el cual, para conjurar el contagio, lo representa internamente como su antídoto (cf. Derrida 1975, p. 201). En ese sentido, el fármaco platónico, en tanto que representante ambiguo e irrupción de la diferencia entre lo interior y lo exterior, entre el bien y el mal, o entre la salud y la enfermedad, corresponde a ese movimiento indecidible que solo puede expulsar el poder del mal, introyectándolo. De esa manera, los límites de la polis y el arje de la comunidad permanecen expuestos siempre ya a un constante desplazamiento, que patentiza la imposibilidad de una transparencia plena de la comunidad política; y es que el pharmakon platónico representa la indecidibilidad de una terapéutica política siempre ya apresada en la repetición de los sustitutivos y en la construcción de los simulacros de la ciudad (Derrida 1975, pp. 254-257).

¿Existe, acaso, un paradigma que sirva como modelo de los paradigmas con que Platón compara el arte político, del mismo modo que el deletreo infantil opera en el Político como modelo formal de todo modelo? Desde luego, en el diálogo del Político, el extranjero de Elea presenta como paradigma de los paradigmas el deletreo infantil, pues constituye un buen ejemplo de lo que es forjar modelos: cuando los niños están empezando a aprender el alfabeto, conviene representarles las letras en sílabas simples, que sirven como modelo, ya que permiten reconocer, comparar y combinar elementalmente las letras y sus patrones de relación, para luego poder formar expresiones complejas a partir de los modelos/ejemplos establecidos (Político, 277e-278d). Ahora bien, el paradigma del deletreo infantil parece constituir únicamente una ejemplificación formal del uso de modelos en general, en un contexto básicamente didáctico, por lo que cuesta creer que sea el paradigma de los paradigmas del arte político.

Sin embargo, el extranjero de Elea plantea un paradigma que sí parece un buen candidato como modelo de los paradigmas políticos: la tejne del tejedor (Político, 279a-b). No en vano, el arte de tejer consiste en la fabricación de cierta protección frente al entorno (en este caso, en la producción de determinado resguardo contra la intemperie), al elaborar un abrigo para el cuerpo, entrelazando en un solo tejido la trama y la urdimbre. Se trata de un trabajo de asociación, reunión y entrelazamiento de los hilos del tejido, que presupone, no obstante, la confección de los propios hilos, es decir, la selección y disociación de las fibras con que se teje (el cardado), así como la torsión de las hebras para confeccionar la urdimbre y la trama (el hilado) (Político, 279d-283a). Pues bien, de modo análogo, el arte político, en tanto que tejne del tejedor regio, también aporta el cuidado de los cuerpos a través de la producción de artefactos, y lleva a cabo determinado entrelazamiento y congregación de los elementos de la ciudad (así como del propio ciudadano) que presuponen ciertas formas de selección, 
separación y torsión de los componentes de la polis $^{23}$. De hecho, la soberana tejne del tejedor político no solo entrelaza las diversas artes cultivadas en la ciudad (estrategia, jurisprudencia, oratoria, etc.), decidiendo su oportunidad y adecuación en el tejido de la polis; además, tras una cuidadosa selección y exclusión de los elementos inútiles, tuerce, combina y entrelaza las naturalezas valientes y las moderadas, de manera que entreteje los caracteres en la más armoniosa comunidad de opiniones, reconocimientos, honores e intercambios recíprocos (Político, 305d-311c) ${ }^{24}$.

Así, pues, en conclusión, el paradigma del tejedor real recoge algunos de los elementos clave de esas otras artes que también suministraron metáforas constitutivas para pensar el arte político. En términos generales, comparte con los otros paradigmas (el pastoral, el cibernético y el terapéutico) cierto énfasis en esa forma de construccionismo que se vincula a la investidura de la actividad política como tejne, o sea, como un conocimiento experto, exclusivo de unos pocos, que proporciona protección y cuidado ante las amenazas de la naturaleza (o ante los riesgos naturalizados), procurando la más armónica disposición del organismo de la polis y de los cuerpos de los ciudadanos.

\section{Conclusión}

Tal vez, para concluir, cabría realizar una interpretación generosa del Político, y considerar que, en este diálogo platónico, se señala brillantemente el núcleo mismo de la problemática política, a saber: la difícil relación entre lo uno y lo múltiple

23 De nuevo, la tejne política platónica, que el eleata trata de introducir bajo el paradigma del tejedor, solo consigue organizar el régimen de lo uno y preservar el principio interno de la comunidad, desechando y excluyendo. Tal vez ésta sea una consecuencia ineludible del intento de concebir la actividad política bajo el signo de la tejne, pues toda producción artificial que combina elementos, también los selecciona. En palabras del eleata: "Veamos si alguna de las ciencias combinatorias constituye voluntariamente un objeto cualquiera aun el más insignificante- de los que son de su dominio, recurriendo a algunos materiales malos y a otros buenos, o bien si toda ciencia descarta, en lo posible, en todos los casos, los materiales malos y toma sólo los apropiados y los útiles y, una vez que los ha reunido en una unidad a todos -tanto los que son semejantes como los que son desemejantes-, produce una obra con una única función y un solo carácter" (Político, 308c).

24 El extranjero de Elea formula su descripción final del tejido político, en los siguientes términos: "Éste es -digámoslo- el fin del tejido de la actividad política: la combinación en una trama bien armada del carácter de los hombres valientes con el de los sensatos, cuando el arte real los haya reunido por la concordia y el amor en una vida común y haya confeccionado el más magnífico y excelso de todos los tejidos, y abrazando a todos los hombres de la ciudad, tanto esclavos como libres, los contenga en esa red y, en la medida en que le está dado a una ciudad llegar a ser feliz, la gobierne y dirija, sin omitir nada que sirva a tal propósito" (Político, 311b-c). 
en nuestras comunidades e instituciones compartidas. En un tono más esperanzador, podríamos incluso añadir -siguiendo a Castoriadis- que el Político formula una auténtica invitación a asumir la autoinstitución permanente de nuestra vida social compartida; no en vano, en el diálogo se reconoce que la legislación política es una actividad constantemente reemprendida y sujeta a transformaciones, la cual requiere del entendimiento y autodeterminación racional del demos. Y es que ya no hay pastores divinos que pudieran eximirnos de la autolegislación social, tutelando constantemente nuestras almas, ni existen estructuras institucionales codificadas de una vez por todas, que puedan sustraerse al devenir de los asuntos humanos; de manera que no nos quedaría más que hacernos cargo de la autoinstitución democrática permanente de la polis (Castoriadis 2005, pp. 180-181).

Sin embargo, no parece que podamos conciliar fácilmente semejante interpretación con el furibundo espíritu antidemocrático de Platón -que el propio Castoriadis denuncia-, ni tampoco podemos olvidar la tensión interna que recorre el intento platónico de fundar la ciudad desde su arje. Y es que la pretensión de establecer el arje de lo político e instituir el régimen de lo uno al interior de la polis (en pocas palabras, la política del arje) solo consigue establecer un remoto ideal de cierta orthe politeia; pero se trata de una corrección política tan alejada de la variopinta textura de la ciudad humana y de la contingencia de nuestras prácticas políticas efectivas, que solo resulta tangible concibiendo finalmente la actividad política bajo el signo de la tejne, es decir, como artefacto o construcción instrumental, dependiente de un conocimiento experto. He ahí la ambigüedad del remedio platónico: la preservación y salvaguarda de la idealidad de la polis pasa por la construcción artificial de una tejne de la política, así como requiere de ciertos sustitutivos, suplementos, copias e imitaciones, de un arje político siempre ya ausente. El mejor ordenamiento humanamente posible de la polis consiste siempre ya, por tanto, en lo segundo mejor, es decir, en la imitación de la orthe politeia y en la construcción del artefacto de la ciudad como un simulacro creíble, persuasivo y útil a la hora de armonizar el conjunto de la representación.

No es de extrañar, pues, que los mitos y las metáforas paradigmáticas constituyan un elemento crucial del juego de ese logos que nos permite dar cuenta del orden de la polis; de hecho, en la ciudad de los hombres, solo por medio de la representación y repetición de imitaciones, copias y simulacros, resulta posible hacer presente el arje de la comunidad. En conclusión, tal vez sea ése el destino fatal de toda arquipolítica, que pretenda transparentar el principio orgánico de la comunidad política y su perfecta unidad interna: está condenada a devenir mimeo-política, o sea, construcción de copias e imitaciones de su propio arje inaccesible, en ese teatro de los simulacros que es la ciudad humana. 


\section{Referencias bibliográficas}

Brisson, Luc (2005), Platón, las palabras y los mitos. Madrid: Abada Editores.

Castoriadis, Cornelius (2005), Sobre el Político de Platón. Madrid: Editorial Trotta.

Derrida, Jacques (1975), “La farmacia de Platón”, en La diseminación. Madrid: Fundamentos.

Esposito, Roberto (2005), Immunitas. Protección y negación de la vida. Buenos Aires: Amorrortu Editores.

Foucault, Michel (1996), “Omnes et singulatim. Hacia una crítica de la «razón política»”, en Tecnologías del yo. Barcelona: Ediciones Paidós.

Platón (1999), Las Leyes. Madrid: Centro de Estudios Políticos y Constitucionales (traducción de José Manuel Pabón y Manuel Fernández-Galiano).

(1988), "Político", en Diálogos V. Madrid: Gredos (traducción del diálogo, a cargo de María Isabel Santa Cruz).

(1981), "Protágoras", en Diálogos I. Madrid: Gredos, (diálogo traducido por Carlos García Gual).

(1986), República. Madrid: Editorial Gredos, (traducción de Conrado Eggers Lan).

Rancière, Jacques (1996), El desacuerdo. Política y filosofía. Buenos Aires: Ediciones Nueva Visión.

Rosen, Stanley (1995), Plato's Statesman. The web of politics. New Haven: Yale University Press.

Sloterdijk, Peter (2000), Normas para el parque humano. Madrid: Ediciones Siruela. 